\title{
Research of Safeguarding Informationization Technology
}

\author{
Wenlai Shi \\ Jilin Agricultural University, Changchun 130118, China
}

\begin{abstract}
Informationizationon is the trend of world development. It is an important force to promote economic and social change. The level of informationization has become a measure of a country's comprehensive national strength and competitiveness of the important indicators. The Government has put education informationization as the main direction of the current education reform in China. From government to school education, informationization regarded as an inevitable choice for the future sustainable development of the school. Instructional informationization technology has become the general trend of development of the domestic higher education teaching, and continuously improve teaching informationization technology and provide strong support for a new round of education reform. With the rapid development of modern educational technology, the demands towards research on safeguarding instructional informationization technology becomes more and more urgent. This paper discusses basic structure of safeguarding instructional informationization technology in higher education. Combining analysis on its efficacy and localization, and gives expectation on safeguarding instructional informationization technology.
\end{abstract}

Keywords: Instructional informationization; Safeguarding technology.

\section{Introduction}

\subsection{The Introduction of Instructional Informationization and Instructional Informationization in Higher Education}

Instructional informationization is based on the teaching infrastructure, systems and resource construction, organization and management of information under the guidance of modern education theory and concepts [1]. Full use of informationization technology, modern education methods to achieve the diversification of forms of teaching organization, teaching content digitization, teaching methods information. Thereby expand channels of informationization exchange between teachers and students, improve teaching efficiency, expanding the scope of the reform process of teaching. Instructional informationization technology is informationization technology as a teaching system of basic elements. In various fields of teaching, it widely used in all aspects, and promote the modernization of teaching, achieve a reasonable and effective allocation, and utilization of the process [2]. In the teaching process, comprehensive use of the computer as the core of modern informationization technology, reform the traditional teaching philosophy, teaching methods and effectiveness of the process. Informationization technology and teaching process of mutual integration is the process of teaching information. The essence is the use of advanced computer technology, network technology, and multimedia technology, to achieve the teaching basic network platform, teaching digital informationization resources, teaching and scientific management. In order to achieve the modernization of daily teaching activities. This is a process of change teaching thought, and teaching concept. This is also in view of informationization on new teaching systems analysis and integration process, with the ultimate goal is to achieve informationization teaching. In view of the informationization to analyze and integrate the new teaching system process. The ultimate goal is to achieve informationization teaching.

\subsection{The Introduction of the Safeguarding Instructional Informationization Technology}

Instructional informationization technology is the application of modern informationization technology in the field of education. Safeguarding technology is usually some kind of technical support in some medium or carrier to provide a display of subjective and objective. Safeguarding instructional information is actually educational media-based educational technology facilities provided, devices and technical methods and other aspects of real and virtual support. It aims through 
the combination of hardware and software to make the teaching of information technology to develop and continue to grow [3].

Currently, teaching informationization technology has included education network, remote education, education integration, education and interactive education, and education office automation management automation. In the near future, the Bluetooth wireless transmission technology education will be universal wireless informationization technology. It is an important support. A variety of status and trend mentioned above can be expressed as a variety of technical form. In the education process, it is actually for the teaching of informationization technology to provide technical support.

\section{Basic Structure of Safeguarding Instructional Informationization Technology}

\subsection{Educational information resources}

\subsubsection{Network education information resource}

Online education information resource is through human selection, organization, orderly, and effective for learners to develop their own set of useful information. Educational information resources organization has become a fact of online education information resources organization, which is a major point of teaching information technology security.

\subsubsection{Educational Resources Existing Form and Operation}

(1) Multi-media teaching materials: the textbook is the use of multimedia technology multimedia, hypermedia technology in particular, the establishment of teaching content structured, dynamic, and figurative representation.

(2) Resources Globalization: to use of the network, especially Internet can make educational resources of all the world into a sea of information. Education for the majority of users to share.

(3) Individualized instruction: the use of artificial intelligence technology to build intelligent tutor system is capable of teaching and provide assistance based on students with different personality characteristics and needs.

(4)Learning autonomy: due to student-centered education thought increasingly recognized, the use of Safeguarding informationization technology self-learning has become an inevitable development trend.

(5)Cooperative activities: learning activities through cooperation is the current direction of international education development.

(6)Environment Virtualization: Modern has emerged a series of virtual educational environment, including virtual classrooms, virtual laboratories, virtual campus, virtual learning community, a virtual library, which must be brought virtual education.

In addition to the information resources, human resources are extremely valuable educational information resources. Under through computer networks, learners cannot time and space constraints, access to talent from around the world. They do not exert any pressure on the case to help learners to introduce what they have the knowledge, experience to the learners, particular skills and abilities.

\subsection{Education Information Resource}

Education Information Resources environment is the teaching of information resources which circumstances and conditions. There are distributed, mobile and other conditions affect educational information resources.

On the current application point of view, today introduced the Internet in schools, education and conventional satellite transmission of television programs, compared to the campus closed-circuit television education, technical application conditions are a gigantic step forward. But in the past, educational technology does not solve the problem, such as the problems in practice between the individual and the individual structures through collective, individual relations and social factors are not the ultimate solution. Thus, the Internet does not mean that the import campus to solve all the problems [4]. Educational Technology is not just use of media research, the communication and 
interaction between people in the process of education and teaching must be regarded as the focus of educational technology research at present and in the future.

\subsection{The hardware of teaching information}

The main point of the teaching information hardware is the physical entity which is realized by the teaching information technology. The key is the multimedia technology platform based on the network.

(1) The campus network is the foundation of the school teaching informationization construction.

(2) Informationization classroom is the forefront of the application of information technology in schools.

(3) Equipped computer is also an important part of the School of Information Technology building.

Another part of the hardware part should be able to use information technology education teachers in the teaching process. In addition to the teaching of information technology to bring innovative education ideas and methods, the main thing is to bring teaching model changes. All these requirements on teachers teaching the application of information technology in teaching.

\subsection{Teaching information software}

(1)In a broad sense, all the text, the way and the mode of the hardware service belong to the software, it cannot survive without the concept of hardware.

(2)In a narrow sense, the teaching of information technology is mainly used to support a variety of computer and network operation of the program or module.

(3)A good teaching information software should be developed directly to teachers and creative staff, which is used to integrate, process and manage the development of multimedia information.

\subsection{Technical standard of teaching information}

The main contents of the technical standards of teaching information include the following aspects:

(1)Technical standards related to the educational environment and resources construction.

(2)Educational technology competency standards related to educational personnel.

(3)Educational technology application level standards related to educational institutions.

(4And educational technology industry and the application of the relevant professional norms.

(5)Network education related to the specialized norms.

Educational information resources, education information resource environment, teaching information technology hardware, and software are five contents of teaching information technology. It is a matter of safeguarding technology. Its concrete manifestations are the following: education network technical support, remote technical support education, integrated education and technical support, technical support interactive education, education management and technical support office.

\section{The limitations of Safeguarding Instructional Informationization Technology}

In the process of promoting the teaching of information technology, including computer technology, network technology, multimedia technology and other technical support to obtain a very significant success. Technology to improve the effectiveness of human activity. And with technology continues to upgrade, this performance can be significantly improved. However, the effectiveness of the application of any technology has its limitations place, especially in the education of such "artificial" and "human" activities in many non-technical factors influence will never disappear. It is because of the role of non-technical factors will continue to reflect on the process of education [5]. Therefore, safeguarding instructional informationization technology cannot replace the impact of non-technical factors, safeguarding instructional informationization technology is both effective technical support, but also have limitations.

\subsection{Limitations Education Network Technology}

Network Education cannot replace traditional teacher education embodied in "teaching" style charm, including how teachers in the classroom with the appropriate tone, eye contact, gestures, etc. to create a suitable for students to hear, think, feedback classroom atmosphere. This network 
education is difficult to do. The network is very easy for students to get a lot of repetitive information. Although broadened my horizons, in fact, the effectiveness and efficiency is not high. It is difficult and conscious compared to guide students to read and think about the kind of heuristic methods. In addition, too many students will rely on network education of traditional culture to have a sense of exclusion, this sense of exclusion is inevitable that traditional education good things to be negative, which is not conducive to our next generation to absorb the essence of excellent traditional culture.

\subsection{Limitations of Remote Technical Support of Education}

Distance education is mainly reflected in the limitations of time and space due to differences in distance and geographical differences in habits and generate educational ideas. Education tend to rely on the teacher to guide the thinking. It is basically a simple "completely copy". When you want to obtain knowledge of the outside world they lose their individual characteristics, or not in conjunction with their actual situation to have a choice to accept. This phenomenon will be really useful educational resources wastage, and lost the meaning of education.

\subsection{Limitations of Educational Integration Technology}

Education is a very special kind of behavior. Although there are a lot of educational software, educational games, and even educational tapes can be a good teaching activities under certain conditions. However, it is always difficult to show the kind of education most vividly, integration tends to be very mechanical.

\subsection{The Limitations of Educational Interaction Technology}

Interactive education is a certain arbitrariness, traditional education is basically a teacher lecture, supplemented by students' questions plus answers to questions or discussion. And the role of interactive education in middle school students and teachers has been more dilute, the teaching process of random discussion more, so that the flow of educational resources is not clear. Another factor for students to separate the negative cooperative teaching is that students can't feel the charm of teachers' personality. No face to face emotional communication, no longer have the kind of long-term intimacy and friendship forged, the teacher's words and deeds appeal, heart shock and sympathy influence will disappear.

\subsection{The Limitations of Education Office and Management Technology}

And more dependent on the network will be a mere formality handle many realities, site office functions are difficult to be reflected. Charisma is difficult to reflect on management by teaching management information. This will be the manager and the manager is in a relatively isolated situation, sometimes in the face of some new things or difficulties make participants feel very confused.

\section{The Future Prospects of Teaching Information Technology Support}

Remote interaction and integration of modern educational technology will use a two-way interactive communication media. It is based on computer technology, network technology, and multimedia technology, two-way electronic communication technologies, and education and communication theory, modern learning theory based on the close connection [6]. It interactivity, networking, real-time, integrated basic characteristics and adaptability to this mode of education has brought a strong technical support and development opportunities.

The number of future educators are likely to be reduced over a period of time, but the basic quality will be greatly improved, because they will use information technology to disseminate teaching educational methods and principles, so that a large number of educated quickly grasp educators and educational information on their own.

\section{Conclusion}

Teaching information technology development must rely on the development of safeguarding technology. Safeguarding instructional informationization technology has been a certain amount of development and attention, we can use it to promote the teaching of information technology 
development. At the same time, we also note that they have limitations. On the one hand, it need to increase its research efforts, on another hand, it need to take effective measures to overcome these limitations.

\section{References}

[1] Qiu-qing L I. Research of Safeguarding Instructional Informationization Technology in Higher Education [J]. Computer Knowledge and Technology (Academic Exchange), 2007, 11: 138.

[2] Gibbons P. Assessing Risk and Safeguarding Rare Library Materials during Exhibition Loans [J]. International Journal of Risk and Contingency Management (IJRCM), 2016, 5(1): 15-25.

[3] Education D F. Information sharing: advice for practitioners providing safeguarding services to children, young people, parents and carers: March 2015[J]. Department for Education, 2015.

[4] Zhang H. An Analysis of Teaching Management of College English in the Context Informationization [J]. Journal of Leshan Normal University, 2013.

[5] Canelos J, Taylor W. A Networking Information Processing Strategy and the Learning of Field Dependents Receiving Visual Instructional Information [J]. Journal of Experimental Education, 2015, 50(1):42-46.

[6] Hong M A. Vocational Colleges Top-level Design Program [J]. Software, 2013, 3: 039. 